\title{
The market for animal welfare
}

\author{
Jayson L. Lusk
}

Accepted: 30 November 2010/Published online: 16 April 2011

(C) The Author(s) 2011. This article is published with open access at Springerlink.com

\begin{abstract}
Animal welfare is emerging as one of the most controversial issues in modern livestock agriculture. Although consumers can buy free range products in niche markets, some have argued that existing markets cannot solve the animal welfare dilemma because there are individuals who care about animal well-being who do not eat animal products. This paper proposes a market-based solution to at least partially manage animal welfare externalities. After discussing the current lack of market incentives to promote farm animal well-being, a potential scheme to quantify and trade units of farm animal wellbeing is proposed. The potential merits and efficacy of an animal welfare market are also discussed.
\end{abstract}

Keywords Animal rights - Cap and trade - Livestock · Niche markets - Vegetarian

$\begin{array}{ll}\text { Abbreviations } \\ \text { AWA } & \text { Animal Welfare Approved label } \\ \text { AWBU } & \text { Animal well-being unit } \\ \text { FOWEL } & \text { Fowl welfare model } \\ \text { HSUS } & \text { Humane Society of the United States } \\ \text { NAWBS } & \text { Normalized animal well-being score } \\ \text { SOWEL } & \text { Sow welfare model }\end{array}$

J. L. Lusk ( $₫)$

Department of Agricultural Economics, Oklahoma State

University, 411 Ag Hall, Stillwater, OK 74078, USA

e-mail: jayson.lusk@okstate.edu

\section{Introduction}

If someone is truly concerned about the well-being of farm animals and wants to change current production practices, what are the avenues currently available to achieve this end? One can reduce meat consumption or become a vegetarian. But what if this isn't enough? Once a consumer has decided to eat cage free eggs or has given up animal products altogether, the opportunities to express preferences for improved animal welfare in the current market environment are limited. Given this reality, it is not surprising that some people have turned to non-market activities: to activism, to the courts, and the ballot boxes, seeking to improve farm animal well-being. It is estimated that about 50-60 pieces of legislation regarding animal welfare are introduced in the US Congress each year (Rollin 2004), and citizens in several US states have voted on constitutional amendments to ban certain animal production practices. These extra-market activities are a result of a belief among some people that markets have failed to provide adequate standards of farm animal care. Many animal activist groups utilize a civil rights rhetoric, imagining that change must come through litigation and protest. The consistent and repetitive analogy between animal welfare and human slavery serves to reinforce this mindset (e.g., see essays in Sunstein and Nussbaum 2004). And, it is against this mindset that livestock production industries have adopted a fighting mentality. What is missing is some fresh thinking in the debate.

The purpose of this paper is to provide some economic insights into the current animal welfare debate and to propose a mechanism which has the potential to improve animal welfare without resorting to lawsuits, legislative initiatives, or protests. It is useful to begin by considering the policy alternatives that are currently advanced to improve farm animal well-being. 
Policy options to reduce the economic externalities associated with animal welfare

Conventional economic theory asserts that competitive markets efficiently allocate resources to their most valued uses. This Fundamental Theorem of Welfare Economics implies that altering the prices and quantities produced by a competitive market cannot produce a higher level of aggregate well-being in the utilitarian sense. These ideas, which were mathematically formalized by authors such as Arrow and Debreu (1954), have led economists to set competitive market outcomes as the benchmark from which to judge the suitability policy proposals.

One well-known situation in which the utilitarian welfare-maximizing property of competitive markets breaks down is when the production or consumption of a good generates an externality; when a cost or benefit is conveyed on a third party not involved in the original transaction. When externalities exist, the market price of a product will not reflect the full social costs (or benefits) of production, and consumers will consume too much (or too little) of the good from an aggregate utilitarian perspective. The potential existence of externalities in the production of meat has led some to argue that certain policies can improve the allocation of scarce resources. In particular, some argue that animal welfare (or animal suffering) is an externality generated by the production of meat, milk, eggs, or other animal products. To illustrate, consider Fig. 1, which presents a simple characterization of the meat production process. Farms purchase animals and other inputs (e.g., corn, labor, fencing) to produce meat. Farmers and meat packers negotiate with two types of meat consumers (type I consumers, carnivores, who only care about meat consumption, and type II consumers, compassionate carnivores, who enjoy meat consumption but are also concerned about animal suffering). These negotiations and interactions result in a market price for meat products.

In the process, however, farms can be thought of as producing another output, animal welfare, which is not generally factored into the price of meat. If current levels of animal welfare are particularly low, as is argued by many authors (e.g., Singer 2002), then the production of meat creates a negative externality - animal suffering. The negative externality is a "cost" imposed on a third party, which is represented by the type III consumer shown in Fig. 1-vegetarians and vegans-who are saddened by the current state of animal production (type II consumers also bear the costs of the externality). Because the price of meat does not take into consideration the disutility experienced by vegetarians (or compassionate carnivores) from animal suffering, then more meat will be produced than is desirable in a utilitarian sense as judged by the aggregate welfare of all consumers. ${ }^{1}$

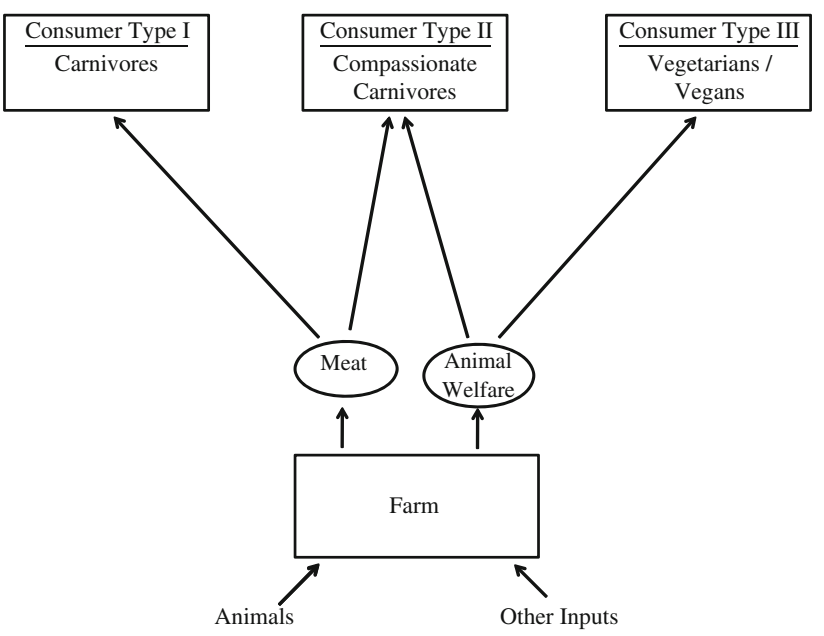

Fig. 1 The production and consumption of meat and animal welfare

Although animal welfare regulation can be motivated based on other grounds (e.g., ethical or moral), the externality argument provides a convenient means to analyze the effects of different types of policies while working within well-established economic theories. In what follows, I consider three pre-existing policies that have been proposed to reduce the animal welfare externality associated with meat consumption before turning to a new proposal: a market for animal welfare.

\section{Meat taxes}

A traditional solution to deal with negative externalities is the use of the so-called "Pigovian tax," originally suggested by Arthur Pigou (1920) and further developed by authors such as Baumol (1972). The idea is that a tax can be levied against the good traded in the market to force producers and consumers to pay the full social cost of production. An efficiently designed Pigovian tax would increase the price of the market good by exactly the amount needed to offset the costs of the negative externality on the third party, returning outcomes once again to the welfare-maximizing result of the competitive market.

\footnotetext{
${ }^{1}$ It could also be argued that the primary cost of current animal production practices are borne not by vegetarians but by the animals themselves. Singer (2002) and others have argued that animal wellbeing should enter directly into the utilitarian calculation of policies; if one takes this step, then "social welfare" includes the welfare not just of humans but of animals as well. Whether one actually includes animal well-being in the utilitarian calculation is somewhat immaterial to the present argument. Either way, meat production generates a negative externality, and "society" - whether it includes animals or not-is over consuming meat. Including animal well-being in the utilitarian calculation only changes the size of the externality and the extent to which overconsumption is taking place (also see Lusk and Norwood 2011 for discussion on the limits of including animal well being in utilitarian, cost-benefit analysis).
} 
In the case of animal welfare, several groups have proposed meat taxes. For example, People for the Ethical Treatment of Animals (PETA) currently sells "Tax Meat" tote bags and t-shirts. ${ }^{2}$ Although the proposals are often vague as to the exact size of the tax or the methods of implementation, then general idea is that a tax on meat would reduce intake of meat; and therefore would result in less animal suffering. While it is possible that meat taxes could partially alleviate the negative externality associated with modern livestock farming practices, there are several shortcomings of the policy concept.

The effects of a meat tax are mitigated by the fact that consumer demand for meat is relatively insensitive to price changes. Most estimates suggest that a $1 \%$ increase in the price of meat would cause a $0.6-0.9 \%$ reduction in the quantity of meat purchased (Gallet 2010). Thus, a meat tax would be probably be effective at raising revenue for the government, but less effective at curbing meat consumption. But, more importantly, the primary effect of a meat tax would be on the quantity of animals living not on the quality of animal lives. As Cowen (2006) argued (p. 42), "Contrary to common intuition, a tax alone does not necessarily improve animal welfare. If we tax meat consumption, without any other policy changes, some animals will be reallocated to the other sectors."

A related issue is that, depending on how one wants to conceptualize the issue, animal welfare can be considered a positive externality in need of subsidy rather than tax. ${ }^{3}$ As argued by Norwood and Lusk (2011), some farm animals, such as beef cattle, arguably live an overall good life, which means that a positive-rather than negativeexternality potentially exists for some animal products. The over-arching point is that meat taxes are a blunt instrument in improving animal welfare in the sense that the effects on animal welfare are indirect and, as Cowen (2006) noted, potentially counterproductive. It must also be mentioned that although Pigovian taxes can, in theory, offset a negative externality, the theory assumes perfect knowledge by the regulator about the slope of the demand curve for the traded good, and about the size of the externality costs. Clearly, there is a great deal of uncertainty about such matters and, as such, there is little reason to believe that a Pigovian meat tax would have the impact in practice that is promised by the theory.

\footnotetext{
${ }^{2}$ For example, see http://www.cafepress.com/petastore.309786585.

3 Cowen (2006) even argues that "it may be desirable to subsidize rather than tax meat consumption, even from the point of view of vegetarian animal lovers" if meat production is more humane to animals than, say, use of animals in laboratory research.
}

Process regulations

A popular tactic pursued by animal activist groups such as the Humane Society of the United States (HSUS) and the Farm Sanctuary is the use of state ballot initiatives and state-level legislation to enact regulations which seek to prohibit livestock producers from using certain processes or production practices. For example, the HSUS has worked to enact bans on use of veal crates (beef calves) and use of gestation crates used in pork production in states such as Arizona, Florida, and Oregon. These policies target specific farm practices and seek to reduce the externality problem at its source. For example, in Fig. 1 a process regulation seeks to change the link between the farm and the production of animal welfare as an output before it reaches consumers.

Process regulations are popular, in part, because of their simplicity and seemingly intuitive appeal in reducing the externality. Unfortunately, process regulations can have counter-intuitive effects. In particular, process regulations, such as the ballot initiatives that have banned use of gestation crates or battery cages (poultry), often do not completely specify the alternative systems that could be adopted. In fact, following the passage of Proposition 2 in California in 2008, which was pushed by the HSUS to eliminate the use of cages in egg production, one large farm, J.S. West Incorporated, made a major capital investment to install more spacious cages because the proposition simply said that the animals had to have room to fully extend their limbs. As such, passage of Proposition 2 may not eliminate the use of cages despite the fact that this was the original intent of the animal activist groups. Simple bans on production processes cannot guarantee improvements in farm animal welfare without other regulations. It is possible, for example, to imagine open barn systems used for chickens kept for egg production actually achieving lower levels of hen well-being than some enhanced or enriched cage systems. Moreover, with the absence of trade restrictions, banning a practice in one state or location simply serves to change where food products come from but not how animals are raised (e.g., see Sumner et al. 2008).

Meat labels and certification

Because taxes and process regulations provide indirect and potentially counter-productive means of improving animal welfare, many organizations have sought to develop meat labels and brands which advertize having attained a higher level of animal well-being for the livestock in question. An example is pork sold with the Animal Welfare Approved (AWA) label. The labeling standards are developed by the non-profit Animal Welfare Institute, which audits and 
certifies farms using the AWA label to ensure that the farms follow practices deemed to promote higher levels of animal welfare. Chang et al. (2010) show that there are well over 2,500 different types of eggs currently sold in the US enabling consumers to choose between eggs from hens produced in organic systems, free range systems, and barn systems, all of which, arguably, increase animal welfare relative to hens living in conventional battery cage systems.

Although the market for such products is growing (see Abrams et al. 2010), meat labels are unlikely to solve the externality problem associated with animal welfare. One of the main reasons is that labels advertising higher levels of animal well-being only affect one type of consumerconsumer type II in Fig. 1, the compassionate carnivore. Consumer type I, the carnivores, do not value higher levels of animal well-being and are not willing to pay for certified meat products. Consumer type III, the vegetarians and vegans, do not eat meat. ${ }^{4}$ Thus, even though many vegetarians and vegans care a great deal about farm animal welfare, the existence of certified meat labels does nothing to allow them to act on their preferences because the two products from the farm-meat and animal welfare-are inextricably linked or coupled together in the labeling scheme; a consumer can't have one without the other.

Labeling leaves consumer type II, the compassionate carnivore, to bear the responsibility of resolving the externality problem. While some consumers are willing to pay premiums for certified or more humanly labeled meat products (e.g., see Carlsson et al. 2007; Lusk et al. 2007; Tonsor et al. 2009), that does not mean they will if they do not have to. Type II consumers act on the basis of private incentives to purchase more humanly-produced meat (e.g., they think it tastes better or is safer-see Norwood et al. 2007), but economists are generally skeptical of the notion that people are sufficiently altruistic to wholly internalize the cost of the externality. In particular, one can conceptualize animal welfare as a public good (the consumption of which is non-trivial and non-excludable), and even type II consumers face incentives to "free-ride" off contributions of others (see the discussion and examples in Norwood and Lusk 2011). It is for this reason that authors such as Conner (2004, p. 32) have argued in the context of organic foods that, "voluntary labeling is not sufficient to address the market failures, entry barriers, and biases of current policy..." Thus, while existence of label schemes

\footnotetext{
${ }^{4}$ Figure 1 is, of course, a simplified depiction of reality. Many consumers who are somewhere between types II and III currently eat some meat, but would eat more if they could be assured that the meat came from animals produced using practices which delivered high levels of welfare. Likewise, some type I consumers might place some small value on improved animal well being, but an amount that is less than the cost of providing the higher standards.
}

or other certifications, such as the AWA label, have the potential to reduce the effects of the animal welfare externality, there is little reason to believe that their existence would generate outcomes that maximize aggregate societal welfare.

\section{A new proposal: a market for animal welfare}

Although food labeling seeks to use market forces to promote higher levels of animal welfare, the approach is inherently limited because it requires coupling two products of farm production, meat and animal welfare, and in so doing prevents type III consumers from expressing their demand for higher levels of animal welfare. For example, a vegan will not buy AWA pork just because it is AWA certified. But, would a vegan "buy" more animal welfare if it were decoupled from meat consumption? Potentially, but only if there were a separate de-coupled market for animal welfare.

In a general sense, an externality exists because of a missing market. An externality exists because a third party is forced to pay a cost without being asked whether they wanted to buy a product. As such, economists often recommend solving the externality problem by requiring firms to internalize the externality-regulating firms to take ownership of all their outputs, some of which are costly to own. At present, farms produce an output-animal welfare -for which there is no market price. Because the price of animal welfare is effectively zero, it is only reasonable that profit-maximizing farms place little value on generating this particular output. Luther Tweeten argued that (2010, p. 11), "St. Augustine called for people to 'Love God and do as you please.' The economist advises to 'Price right and do as you please.'" His insight suggests that when markets are working well, there is little to be done to improve the aggregate well-being of the parties involved. As indicated in the foregoing discussion, however, markets do not always work well, and in particular, the price is not always right in the presence of an externality. In fact, in this case, it seems that it is not just that the price isn't quite right, but that there is no price at all: to wit, here is presently no de-coupled market for animal welfare in which buyers and sellers can interact to determine the "appropriate" level of animal well being. ${ }^{5}$

\footnotetext{
${ }^{5}$ It could be argued that the current non-existence of a separate market for animal welfare suggests that such a market is not viable. This is a particularly strong interpretation of the efficient market hypothesis (Fama 1970), and is reminiscent of the old joke about an economist walking past a dollar bill lying on the ground, refusing to pick it, reasoning that if it were really a dollar bill, someone else would have pick it up. The fact that there is no current market for animal welfare either means that the market is infeasible or that there is an unnoticed arbitrage opportunity that has yet to be exploited. This paper argues that the latter is the case.
} 
Succinctly put, a market for animal welfare would consist of giving farmers property rights over an output called animal well-being units (AWBUs) and providing an institutional structure or market for AWBUs to be bought and sold independent of the market for meat. A more precise discussion of how AWBUs are calculated and how a decoupled market for animal welfare could operate is included in a following section. Further on, I consider some of the potential consequences that the existence of such a market might produce relative to existing policy proposals.

One of the problems with the aforementioned Pigouvian meat tax is that although it is possible in theory to imagine a tax of a properly-set amount that could result in an efficient allocation of resources, in practice there is insufficient knowledge to set a precise tax. One of the key merits of markets is not just that they allocate resources efficiently (as posited by the aforementioned Fundamental Theorem of Welfare Economics), but that the process of resource allocation creates information, which is embodied in market prices. This insight, perhaps associated most closely with Hayek (1945), suggests that were a market for AWBUs available, a market price would emerge that balanced the competing demands of those who want higher levels of animal well-being against those who would incur the cost of providing high levels of care, without a policy maker needing to know in advance the "appropriate" level of animal care. And, unlike a static Pigouvian tax, market prices are dynamic, continually adjusting the changing demands and costs in a way that would continually balance resource allocation given current states of knowledge.

In a general sense, prices serve important allocation and information roles. When there are multiple people negotiating to acquire a resource, a market enables the allocation of the scare resources to the people who value them most. This allocation is achieved via the market price. Thus, prices are not only the mechanism by which the allocation takes place, but price also informs. Prices reveal to sellers whether they should make investments to increase manufacturing capacity and they reveal to buyers the opportunity cost of buying one good versus another. Prices reflect the costs involved in production and the demand for the resources used to produce the good, and in a dynamic market economy, rapidly adjust to efficiently equate the number of willing buyers with the number of willing sellers.

Another shortcoming of the meat tax is that, although it would likely result in a modest reduction in meat consumption, it would not necessarily produce higher levels of animal well-being. In contrast, an animal welfare market would be directly tied to the well being of animals. This was also a problem with process regulations-they were single-minded attempts to improve animal well-being that could have unintended consequences. As described in a following section, calculation of AWBUs would entail a more holistic conception of animal well-being that is aimed not at particular processes per se, but rather on animal well being.

Moreover, a benefit of a market for AWBUs, as compared to process regulations, is that an AWBUs approach provides incentives for producers to improve animal wellbeing at the lowest possible cost by focusing producer and consumer attention on an outcome (animal well-being) rather than a particular process or technology (i.e., cages, stalls, etc.). Those issues for which animal activists can garner the largest political support (e.g., elimination of cages) may not be those that can provide the largest change in animal well-being per dollar spent. By focusing on outcomes and letting producers worry about how to achieve the outcome, markets could enable innovation in livestock production methods and encourage producers to seek cost-effective means of improving animal well-being.

Finally, unlike meat labels, a market for animal welfare could engage type II and III consumers in a way that meat labels cannot by decoupling animal well-being from the purchase of meat or other animal products.

What is needed is a decoupled market price for animal welfare. In principle, a framework can be established to give livestock producers clearly defined property rights to AWBUs, which relate both to the number of animals on a producer's farm and the quality of the animals' lives. Thus, livestock producers would supply AWBUs to the market. Who would want to purchase AWBUs? Anyone who cares about the well-being of farm animals is a potential buyer (e.g., type II or type III consumers shown in Fig. 1). In such a system, people passionate about animal well-being have a direct and tangible means to get what they want. Such a system would work to achieve an overall level of animal well-being in such a way as to balance the costs of providing higher levels of care with people's demand for it; all through, the price of AWBUs would be determined by the interaction of buyers and sellers.

Creating a market for AWBUs would convey the opportunity, but not the obligation, to participate. Farmers and livestock producers would voluntarily choose whether to participate (and be audited periodically), but presumably, many would do so because they would gain access to a new market and garner an opportunity to profit. Likewise, only those citizens who have the means and the interest to do so would buy AWBUs. In this sense, a market for AWBUs would also separate rhetoric from reality. It is easy to say improvements in animal welfare should be enacted, but this is a different matter from being willing to pay the costs of the improvement. A market for AWBUs imposes the cost of animal welfare improvements on the people who want it. This does not mean that some of the same incentives for free-riding that exist with regard to 
meat labels wouldn't also exist with an AWBU market, only that the AWBU market would expand the pool of potential buyers to those people who currently buy little to no meat. In what follows, I outline how such a market could be constructed in practice; but first, I consider the ethical considerations of such a market.

\section{Ethics of an animal welfare market}

Some of the most prominent and influential writings on animal welfare and animal rights have come from moral philosophers and ethicists (e.g., Singer 2002; Francione 2004; Regan 2004; Wise 2004), and as such, it is useful to consider the merits of a market for animal welfare in the context of this literature. Most philosophers and ethicist who have written about animal welfare advocate for dramatic changes in the way that farm animals are currently treated. The starting point of argument usually stems from the logical position that suffering (or happiness) should receive equal consideration regardless of its source: whether it be a human or an animal. To differentiate between the suffering of humans and the suffering of animals is, according to these authors, to draw an arbitrary line that has no logical bearing; it is an act often referred to as "speciesism".

Although ethicists often agree on the premise of equal consideration of suffering, they part company when evaluating moral consequences of policies. Differences result from common lines of disagreement related to consequentialism versus deontologicalism. In particular, authors such as Singer (2002) take a consequentialist or utilitarian perspective, arguing that the "rightness" of an action depends on its overall outcomes to all parties involved. By contrast Francione (2004), Wise (2004), and others tend to make deontological arguments, asserting that animals should have particular rights.

Deontological ethicists would almost certainly believe that it is "unethical" to trade animal well-being or AWBUs in a market because doing so would violate the rights such ethicists believe animals do or should possess. Deontological arguments against the use of an animal welfare market might take the form: "Well-being is infinitely valuable because all animals deserve humane treatment" or "We need to recognize that there are some things that money can't buy and other things that money can buy but shouldn't."

The existence of a market for animal welfare clearly will not address the concerns of those who advocate for animal rights. Deontological arguments for animal rights typically advocate for a world that is far different from the one in which we currently live-often one without any human ownership of animals and certainly one in which humans would not eat animals. Thus, a market for animal welfare would likely be deemed as unethical according to deontologists.

However, it must be noted that current deontologists also view most current agricultural production practices as unethical. Thus, in this matter, it is perhaps more instructive to take a consequentialist perspective and ask whether the addition of a market for AWBUs would, at the margin, improve the well-being of humans and animals relative to the current state of the world. Ninety-six percent of US consumers currently eat meat (Norwood et al. 2007). As such, current levels of animal welfare are already determined by a market (the meat market), and as such the question isn't whether markets should dictate farm animal well-being, but rather what kind of market will dictate farm animal well-being. Some people object to the idea that animal welfare is a commodity, and argue that, ethically, it should not be traded in a market. But, animal welfare is already being traded or determined by market forces.

Clearly, many animal advocacy groups, such as the HSUS, are willing to use regulation to attempt to improve farm animal well-being, recognizing that the changes will not necessarily result in the abolition of animal ownership. Stated differently, it appears that the HSUS utilizes a consequentialist ethic-arguing that improving the well-being of farm animals through regulation is the ethical thing to do even if people still eat meat. It is interesting that some advocates of animal rights, such as Gary Francione, argued against Proposition 2 in California, which banned the use of cages in egg production (Francione 2008). Although he argued that the consequences of the passage of Proposition 2 were unlikely to produce the kinds of benefits advocated by proponents of the policy, it appears that his primary arguments were deontological - that humans should not own animals and that making animals' lives more pleasurable would only make the general public less willing to sympathize with arguments to abolish animal ownership.

In short, the development of a market for animal welfare can be considered ethical on consequentialist grounds. Such a market has the potential to improve the welfare of animals and the welfare of humans who buy and sell AWBUs. Animals are better off because their living conditions will improve. Some humans are better off because they care about the welfare of animals, whose lives is now improved; and they are willing to pay the price it takes for the improvement. Nevertheless, some consequentialist advocates of improved animal welfare may be averse to "commodifying" animal welfare through a market. Logically, however, it is unclear why improving animal welfare via regulation is any more or less ethical in the consequentialist view than improving animal welfare via a market. A consequentialist is concerned with outcomes not processes; a market process that can generate aggregate 
higher levels of animal and human well-being must be deemed ethical from a consequentialist or utilitarian perspective regardless of whether the outcome was achieved by regulation or by a market for AWBUs. ${ }^{6}$

Finally, some people are likely to object to the idea that it is possible to quantify animal well being in a way that it could be tradable. There are difficulties involved in such a calculation, but as I show in the next section, biologists and animal scientists have devised models to make exactly such calculations and the research shows that such calculates are highly correlated with expert opinion. Moreover, as indicated there are already numerous animal welfare auditing and certification programs, a fact which suggests that people are already quantifying the concept of animal welfare. It is true that people may differ in their subjective beliefs about the effect of certain factors on animal well being, but this need not hinder the creation of a market for animal well-being any more than the fact that trading in the market for computers, cars, and food depends on subjective beliefs about the merits of brand names, consumer report scores, and so on. If a potential trader doesn't like the way animal welfare is calculated in a particular market, they do not have to buy animal-welfare units; but this need not prohibit individuals or organizations from creating a market around a particular concept of farm animal welfare.

\section{Constructing a market for animal well-being}

One of the most important factors to be established before a market can be constructed is to precisely define the good being bought and sold. That is, how is animal well being measured? Measurement of animal well being is no easy task, and there are likely to be controversial issues. However, the task is by no means insurmountable. In fact, there have been many thoughtful discussions of how to aggregate measurements to produce an overall assessment of animal welfare (see Botreau et al. 2007a, b). A variety of approaches are available to determine overall well-being, ranging from informal expert opinion, to simple checklists,

\footnotetext{
${ }^{6}$ An anonymous reviewer asked whether it was ethically "fair" to ask consumer types II and III to pay for the harm done to them by consumer type I. This is an interesting point, but it raises the thorny issue that type I consumers do not believe any harm is being done by their behavior. Moreover, to outlaw sales of AWBUs because they are not "fair" is little different than making a deontological argument that animal well-being should not be commodified or traded. The AWBU market proposed here is a voluntary market, and the "fairness" of the transaction should be judged by the beliefs of willing buyers and sellers. Although it isn't "fair" that a thief breaks into a home and steals a TV, one would hardly fault homeowners for buying locks and security systems to prevent the potential harm done to them. Similarly, whatever one thinks of type I consumers, one cannot fault a type III consumer for wanting to buy AWBUs, and to deny them the opportunity to voluntarily do so hardly seems "fair."
}

to formal models that sum rankings given various measures on the farm-potentially with more weight given to those measures deemed more important to animal well being.

An example of the formal modeling approach is the sow welfare (or SOWEL) model for hog production introduced by Bracke et al. (2002a). The SOWEL model takes data on 37 attributes (such as space per sow, space per pen, etc.) related to 12 different well-being outcomes (such as pain, illness, aggression, etc.) to create a single measure of the well-being of sows (piglet-bearing female hogs) housed in particular production system. Bracke et al. (2002a) reviewed the scientific literature to identify which issues were most important in determining sow well-being. They determined that the most important factor was space per pen followed by health and hygiene status, and exposure to cold. Each of these factors was given a high weight in determining sow well-being. At the bottom of the list were less important issues such as lighting levels and access to wallowing, which consequently were given low weights. Given the weights, different production systems or types of farms can be compared. For example, a farm that performed well on space and health is one that is likely to generate a high level of sow well-being because these are the factors that, according to Bracke et al. (2002a), are highly correlated with sow well being. The overall score of a farm or production system can be normalized, for example, to give the highest possible outcome a score of 10 and the lowest possible outcome a score of zero.

According to the SOWEL model, the typical production system housing sows in individual crates or stalls receives a score of 0.66 whereas a typical enhanced pasture system receives a score of 9.89 . Because the range of scores is from 0 to 10, this implies that typical production systems generate very low levels of animal welfare compared to an enhanced pasture system. Given the way the model is constructed, it is possible for any particular stall or pasture system to receive a higher or lower score depending on the particular practices employed on a given farm. Similar models, such as the fowl welfare (or FOWEL) model, have been constructed for egg production (De Mol et al. 2006). The well-being scores for animal production systems resulting from the SOWEL and FOWEL models have been shown to be highly correlated with expert opinion of animal well-being in the systems (Bracke et al. 2002b; De Mol et al. 2006). That is, when experts are shown different farms and are asked to rate them in terms of the animals' well-being on the farm, such ratings are highly correlated with the mathematical predictions produced by SOWEL and FOWEL models.

For an AWBU market to have credibility, the system for measuring animal well being on a given farm must be objective and transparent. Such criteria would rule out a system that relied solely on expert opinion. A viable 
measurement system is likely to be one designed primarily by the demanders or purchasers of AWBUs; after all, a market will not exist unless something is being delivered that consumers want to buy. At the same time, the system would require the knowledge and input of livestock producers to ensure that compliance requirements were not so restrictive as to prohibit the entrance of sellers. Nevertheless, producers who wish to be certified to sell AWBUs must agree to certain auditing requirements (as current sellers of AWA pork do), and farms would be monitored periodically to establish the appropriate measurement of animal well-being on that farm. Interestingly, several large hog producers have already started to voluntarily install surveillance videos to monitor employees and livestock; and such cameras might also be employed to ease the auditing and compliance burdens. In any event, some type of on-farm auditing by a third-party would likely be required so that buyers of AWBU would be assured that animal welfare was actually delivered at the anticipated level. The costs of the third-party assessors could be paid incrementally through small transactions fees on each AWBU bought or sold or in lump sums by selling the rights to buy or sell on the exchange.

One of the implicit assumptions in many of the formal animal welfare models, such as the SOWEL and FOWEL models, is that animal well-being is compensatory. That is, the good aspects or attributes of a production system can compensate for the bad aspects of a production system. Some animal welfare groups might object to a fully compensatory model. For example, there are likely to be many potential buyers of AWBUs that might find the use of gestation crates in sow production unacceptable no matter how well a farm performed on other measures of animal well being. Such preferences can be incorporated into model like SOWEL or FOWEL by automatically assigning production systems that employ such practices the lowest possible animal well-being score. Similarly, demanders of AWBUs might argue that factors such as farm size or number of employees per animal are important, and there is no reason that a model of animal well-being could not be created that also takes such issues into account.

At this point, many would argue that the task of quantifying animal well-being is too daunting and too complicated to be objectively measured. But, this would ignore the fact that there are already numerous animal welfare auditing and certification programs. The US Department of Agriculture (USDA), for example, lists a variety of animal welfare auditing and certification programs on their web site. ${ }^{7}$ Moreover, the USDA already has a system of facilitating such a program via its Process Verified Program,

\footnotetext{
$\overline{7}$ http://awic.nal.usda.gov/nal_display/index.php?info_center=3\&tax level=2\&tax_subject $=170 \& l e v e 13 \_i d=0 \& l e v e 14 \_i d=0 \& l e v e 15 \_i d=0 \&$ topic_id $=1782 \& \&$ placement_default $=0$.
}

which has been adopted by several producer groups wishing to make labeling claims. Many such programs operate by employing simple checklists, indicating criteria that a farm must meet to achieve the certification. Certainly an AWBU market could be devised based on a simple check-list approach; however, because such checklists tend to focus more on processes than outcomes, a truly successful system is likely to involve some compensatory features that allow producers to employ new and lowercost alternatives for achieving improved animal well-being. In principle, such a system could be created by devising a two to three page check list or score card that an auditor could take onto a farm, the data from which could be fed through simple algebraic calculations to yield the number of AWBUs produced by the farm in a given time period.

Although it must be reiterated that the development of a successful market for AWBUs would require a priori input and negotiation between potential buyers and sellers, some examples and ideas regarding how such units might be calculated and generated are instructive. In particular, imagine a compensatory model like a simplified version of SOWEL or FOWEL being used to create an animal wellbeing score for the farm, which would be normalized between 0 and 1 , where 0 is the lowest threshold for which demanders of AWBUs are willing to give farms "credit" for producing high levels of animal care, and where 1 is some theoretical maximum possible level of animal wellbeing. An auditor would visit an interested farm and compile scores on a number of production attributes, which would be fed into the model to produce the normalized animal well-being score (NAWBS). In general, the score would be calculated as follows:

$$
\begin{aligned}
\text { NAWBS }_{\mathrm{j}}= & \text { Normalized animal well } \\
& - \text { being score for farm } j \\
= & f\left(\text { space per animal }_{j},\right. \text { bedding provisions } \\
j & \\
& \quad \text { feed provisions } \\
j & \text { etc. }) .
\end{aligned}
$$

To illustrate, consider a limited version of the FOWEL model, which would characterize animal (poultry) wellbeing based solely on three farm attributes-(1) the amount of feed given to the layers, (2) the space per hen, and (3) type and availability of nests. Based on the animal science literature, the FOWEL model assigns a raw weight of 25 to feed, 21 to space, and 16 to nests, suggesting that feed is a more important determinant of animal well-being than nest availability. ${ }^{8}$ Table 1 shows the raw and NAWBS for three hypothetical farms that differ in terms of the three

\footnotetext{
8 These are the most important attributes in determining the wellbeing of laying hens according to De Mol et al. (2006). Other issues that are less crucial for laying hen well-being are free-range opportunities or outdoor access (which only receive a weight of 5) and toe trimming (which only receive a weight of 0 ).
} 
attributes. Each farm received a fraction of the overall weight for the attribute depending on its score on a particular attribute-level, which varied from 0 to 1 depending on the extent to which the particular attribute level was the best or worst possible outcome available. As an example, for the attribute "nests," it was assumed that the worst possible level for animal well-being is "no nests," which would yield a score of 0 , and the best possible outcome is "individual nests with bedding," which would yield a score of 1. An intermediary outcome is "group nests with bedding," which might yield a score of 0.5 . The overall raw score for a farm is taken by summing the product of the importance of each attribute by the attribute's score over all attributes. Table 1 shows that hypothetical farm 2 achieves the highest NAWBS at 0.92 ; the reason is simple-this farm provides more space per hen than any of the other two farms and it also provides birds with individual nests and bedding. By contrast, farm 3 had the lowest NAWBS. Although farm 3 scored as well or better than farm 1 on space per hen and nests, it only gives some hens limited food, and because food is such an important attribute to animal well-being, the overall NAWBS for farm 3 falls below that of farm 1 .

In general, the number of AWBUs produced by a farm over a particular time period is determined by the following formula:

AWBUs produced by farm $j$ in time period $t$

$=($ Number of animals on farm $j$ over time period $t)$ $\times$ NAWBS $_{\mathrm{j}} \times\left(\right.$ Adjustment factors $\left._{\mathrm{j}}\right)$.

The formula is constructed such that a producer receives one AWBU for each animal that lives in the highest state of animal well-being. What this formula shows is that the number of AWBUs produced by a farm depends on the number of animals on the farm, the calculated well-being of the animals (the NAWBS for the farm), and an adjustment factor. The adjustment factor takes into account other factors of interest not captured in the NAWBS that consumers of AWBUs may be interested in (such as farm size), factors indirectly related to animal welfare (such as number of employees per animal), or attributes for which one wishes to use non-compensatory decision rules. The base-line adjustment factor is set to 1 . However, suppose that one does not wish to award any AWBUs to farms using a cage system. Then, for any farm using the cage system, the adjustment factor can be set to 0 , making the number of AWBUs produced equal to zero. Alternatively, suppose one does not believe it is possible for animals to receive high levels of care if farm size is too large or if the number of employees per animal is too low. One can easily accommodate such demands using the adjustment factor, and using a series of "if-then"

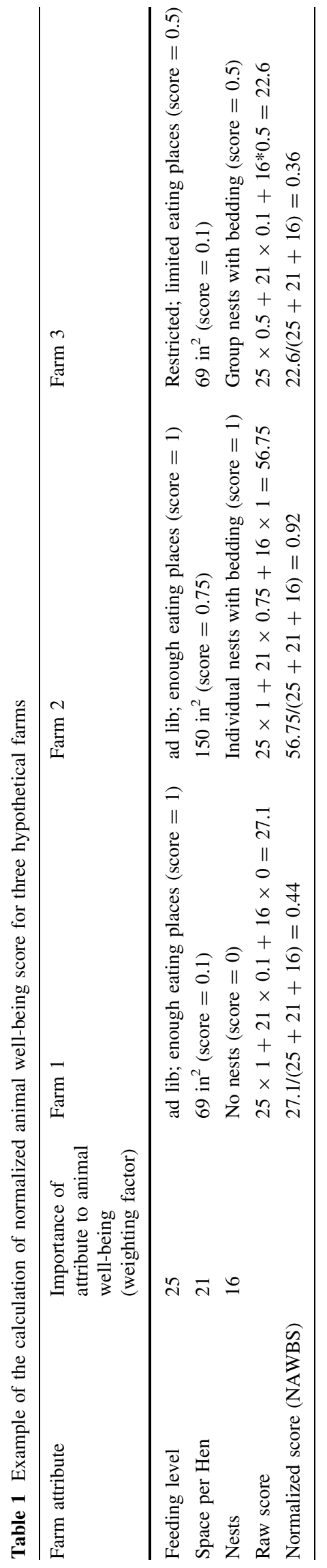


Table 2 Example calculations of animal well-being units (AWBUs) for three hypothetical farms

\begin{tabular}{llll}
\hline & Farm 1 & Farm 2 & Farm 3 \\
\hline NAWBS (see Table 1) & 0.44 & 0.92 & 0.36 \\
Number of layers on farm & 1,000 & 8,000 & 4,000 \\
Adjustment factors & None (factor $=1)$ & Discount for employees (factor $=0.85)$ & Discount for employees (factor $=0.75$ ) \\
AWBUs produced & $0.44 \times 1,000 \times 1=440$ & $0.92 \times 8,000 \times 0.85=6,256$ & $0.36 \times 4,000 \times 0.75=1,080$ \\
\hline
\end{tabular}

conditions. For example, if a farm has an employee-to-hen ratio less than 500:1, then the adjustment factor is set to 1 ; if a farm has a ratio between 500:1 and 1000:1, then the adjustment factor is set to 0.85; if a farm has a ratio 1000:1 and $5000: 1$, the adjustment factor is set to 0.5 ; etc.

The formula shows that the number of AWBUs produced depends on the number of animals on the farm. Some may object to this feature on the grounds that it gives producers incentives to add more animals; however, this is only true if the animals are raised under high levels of animal care. Moreover, the point of the market is to create a mechanism that gives incentives for the greatest number of animals to receive the highest amount of care, and this feature is captured in the above formula.

All the concepts are tied together in the example given in Table 2, which uses the same three hypothetical farms as in Table 1. The first row of Table 2 re-states the NAWBS for the three farms depicted in Table 1. Without any adjustments, a farm will receive the NAWBS for each animal housed on the farm over the time period of interest. For example, farm 1 has a NAWBS of 0.44 , it utilized 1000 layers in egg production, say over the past year, and had no adjustments (i.e., adjustment factor $=1$ ). Thus, farm 1 produced $0.44 \times 1,000=440$ AWBUs for the year. Farm 2 has a much larger flock (8,000 birds), and received a discount for too few employees per bird (adjustment factor $=0.85$ ); however, because the farm performs well in terms of the animal well-being score, each layer on the farm received $0.92 \times 0.85=0.782 \mathrm{AWBU}$ per animal for a total production of $0.782 \times 8,000=6256$ AWBUs for the year. Farm 3 is given a discount for having too few employees per layer, which brings its NAWBS down from 0.36 to $0.36 \times 0.75=0.27$ per animal, yielding a grand total of $4,000 \times 0.27=1,080$ AWBUs for the year. As should now be clear, if some practice is deemed absolutely abhorrent to purchasers of AWBUs, this can be accommodated by setting the adjustment factor equal to zero for any farm employing such practice. In such a case, the farm would be unable to earn any AWBUs until they ceased the practice.

As can be seen from Table 2, a producer has three options to increase the number of AWBUs produced-it can add more animals, increase well-being, or avoid discount factors. The incentive for all farms to improve animal well being is straightforward. The higher the price of AWBUs, the greater the incentive to improve animal care. It seems unlikely, however, that a farm would face much pressure to add more animals simply to increase the number of AWBUs produced unless there was a corresponding change in demand for meat, milk, or eggs. Moreover, a producer only faces positive incentives to add more animals if conditions on the farm are such that NAWBS were to able to established at a high level. And isn't this exactly what animal advocates desire? Indeed, if it became more profitable to produce animals on farms by providing conditions that delivered high levels of animal well-being (which would increase production on such farms), there would likely be a corresponding decrease in the level of production on farms with low levels of animal well being. Thus, the anticipated effects of a market for AWBUs are:

- The average level of animal well-being across all farms, as defined by the average NAWBS, will increase;

- There will be a slight increase in the number of animals produced;

- There will be a redistribution of where animas were produced; more animals will begin to be produced on farms with higher NAWBS; and

- Each of the above affects will be accentuated as the price of AWBUs rises.

Thus far, the discussion has focused on the mechanics of how AWBUs are calculated and produced by farmers. It is now time to say a few words about the market for AWBUs. Just as a farmer collects eggs and brings them to the market for sale; a farmer, once audited, can bring accredited AWBUs to the market for sale. The market could be facilitated by an electronic exchange, where audited producers are given accounts, in which the appropriate number of AWBUs is credited once it has been certified that they have been produced according to the established guidelines. Likewise, buyers can establish accounts by depositing cash. An efficient and well-established price discovery mechanism is the continuous double-sided auction, in which any potential producer can offer up any number of AWBUs for sale at an asking price, and any potential buyer can offer to buy any number of AWBUs at a bid price. A 
Table 3 Example of bid and ask history in a hypothetical market for AWBUs

\begin{tabular}{|c|c|c|c|c|c|c|c|}
\hline \multicolumn{4}{|c|}{ Buyers } & \multicolumn{4}{|l|}{ Sellers } \\
\hline ID & $\begin{array}{l}\text { Time bid } \\
\text { entered }\end{array}$ & $\begin{array}{l}\text { Number of units } \\
\text { demanded }\end{array}$ & Bid (\$/unit) & Ask (\$/unit) & $\begin{array}{l}\text { Number of } \\
\text { units offered }\end{array}$ & $\begin{array}{l}\text { Time ask } \\
\text { entered }\end{array}$ & ID \\
\hline B295 & $8: 00$ & 1,000 & $\$ 0.25$ & $\$ 0.95$ & 1,500 & $7: 45$ & S985 \\
\hline B109 & $8: 25$ & 500 & $\$ 0.28$ & $\$ 0.80$ & 1,500 & $8: 22$ & S985 \\
\hline B295 & $8: 55$ & 1,000 & $\$ 0.35$ & $\$ 0.75$ & 500 & $8: 45$ & S676 \\
\hline B200 & $9: 15$ & 750 & $\$ 0.40$ & $\$ 0.60$ & 1,000 & $9: 25$ & S725 \\
\hline
\end{tabular}

bid-ask improvement rule would be enforced such that any new producer wishing to offer a sale must come in at an asking price lower than any outstanding ask. Likewise, any new consumer wishing to buy must make a bid lower than any outstanding bid. At any time, a buyer is able to accept any outstanding asking price, and a seller is able to accept any outstanding bid price.

For example, Table 3 shows a hypothetical history of "bids" and "asks" in a market for AWBUs. In this example, seller ID number S985 first asked $\$ 0.95$ per unit for 1,500 units at 7:45 a.m. About 15 min latter buyer B295 offered to buy 1,000 units at a price of $\$ 0.25$. S985 decided to revise their bid, and following the bid-ask improvement rule, lowered their ask to $\$ 0.80$. At $8: 25$, a new buyer, B109, made an offer to buy 500 units at $\$ 0.28$. By 9:30, the bid-ask improvement rule has caused the bids-ask spread to narrow.

As indicated, at any time a buyer can accept any outstanding ask (assuming they have enough money in their account to cover the cost) and any seller can accept any outstanding bid (assuming they have the AWBUs to supply). For example, at 9:30 a.m., suppose a new seller S999 choose to accept the buyer B200's bid of $\$ 0.40$ made at 9:15 a.m. With a simple click of the mouse, seller S999 would accept B200's offer, and 750 AWBUs would be subtracted from S999's account and added to B200's account and $\$ 0.40 \times 750=\$ 300$ would be subtracted from B200's account and added to S999's account. Because the bid was accepted, this implies that a market price of $\$ 0.40$ has been observed, and this market price would be listed in the history of market prices for all market participants to see. If S999 wanted to sell more than 750 units, they would either decide whether B295's bid of $\$ 0.35$ was acceptable or they could decide to make an ask at something less than $\$ 0.60$, which is the lowest outstanding ask. Once a transaction has been made, it is assumed that the AWBUs are immediately "consumed."

It is impossible to know the price of AWBUs. Indeed, this is the entire point of creating a market because, as was previously indicated, the market price conveys information that was not previously available to any regulator or any individual buyer or seller. The price will depend, among other things, on the exact formula used to calculate animal well-being and the number of producers and consumers who choose participate. For a given framework used to calculate animal well-being, the more consumers who decide to buy AWBUs, the higher the expected price; conversely, the more producers who choose to participate, the lower the expected price. Ultimately, the market price will reflect the supply and demand conditions for improved animal well being; the costs required to achieve higher levels of animal well-being and what people are willing to pay for better animal care. There is also no reason to expect prices to remain static over time. As producers learn better how to achieve higher levels of animal care at lower costs, they will find it easier to produce AWBUs; holding all else equal, the price will fall. Conversely, if animal welfare grows in importance and more people become more concerned about the issue; holding all else equal, the price will rise.

One final issue related to the construction of the market for AWBUs that has not yet been addressed is how to deal with multiple species of animals. Perhaps the easiest way to accommodate this issue is to have separate markets and separate protocol calculating AWBUs for egg layers, broilers, sow production, milk production, etc. Alternatively, one could construct a centralized market for AWBUs, where another adjustment factor could be used to convert well-being of, say, layers, to well-being of sows. For example, suppose one believes that the well-being of 3 chickens is equal to the well-being of 1 sow. ${ }^{9}$ The AWBUs produced by a layer could be multiplied by $1 / 3$, and all units can be traded in the same market.

\section{The pollution trading analogy}

The previous subsection illustrated that constructing a market for animal welfare is feasible, but detractors are

\footnotetext{
${ }_{9}$ Research has shown that people believe that a particular welfare improvement program for one pig, hen, or chicken is worth 0.742 , 0.581 , or 0.584 , respectively, relative to the welfare improvement for one cow. This data would suggest 1 sow is worth $0.647 /$ $0.779=0.783$ hens (see Chilton et al. 2006).
} 
likely to assert that a market for AWBUs is perhaps a nice theoretical idea, but one with too little grounding in reality. The question is whether such a market will actually workwhether people will actually participate. In this section, I present a useful (if imperfect) analogy between the market for animal welfare and pollution trading markets. The existence of similar markets, mainly related to environmental issues, suggests that a market for AWBUs is no less feasible than is, say, a market for carbon dioxide $\left(\mathrm{CO}_{2}\right)$ emissions. Nevertheless, there are likely to be real obstacles to the development of such a market, and in this section, I ask why consumers and producers, may or may not participate in such a market.

As early as the 1960s, economists began proposing "pollution trading" as a more effective way to deal with environmental issues than traditional command and control policies. Many of these ideas came to fruition in the passage of the 1990 Clean Air Act, which established the first large-scale tradable emissions permits to curb emissions that cause acid rain. The program set a cap on the amount of emissions that an electricity generator could emit, but let those plants wishing to generate more than the cap buy "allowances" from those plants under the cap. The emissions trading markets that were designed have been heralded as a great success by most parties. For example a group of MIT economists argued that,

Not only did [the market trading program] more than achieve the $\mathrm{SO}_{2}$ emissions goal ... it did so on time, without extensive litigation, and at a cost lower than had been projected ... We have learned that largescale tradable permit programs can work roughly as the textbooks describe; that is, they can both guarantee emissions reductions and allow profit-seeking emitters to reduce total compliance costs." (Schmalensee et al. 1998, p. 66)

Likewise, the Harvard economist Robert Stavins (1998, p. 84) indicated, "market-based instruments for environmental production-and, in particular, tradable permit systems-now enjoy proven successes in reducing pollution at low cost." Despite these arguments, there are some fundamental differences with the cap-and-trade markets for reducing $\mathrm{SO}_{2}$ emissions and a market for AWBUs. First, the pollution trading policy involves a government enforced cap on emissions. Second, the market consists of pollution emitters trading with one another. It is possible to imagine an AWBU market designed around a cap, where farms must that have lower levels of animal welfare must buy allowances from farms that produce higher levels of animal care. In this context, it is probably more useful to refer to a "minimum animal welfare standard" rather than a cap because with animal welfare the regulator is attempting to encourage more production of a certain good (in this case high animal welfare), whereas with pollution the regulator is attempting to generate less production of $\mathrm{SO}_{2}$ or $\mathrm{CO}_{2}$. That is, most pollution trading sets a maximum constraint, whereas animal welfare regulation would set a minimum constraint. One difficultly with the pollution caps (or the minimum animal welfare standard) is that they require the regulator to know the appropriate level at which to set the cap. Thus, in many ways, the regulator faces the same problem mentioned above with regard to the Pigouvian tax-a lack of knowledge about the appropriate price (or in this case quantity) to set.

Nevertheless, there is reason to believe that a market for AWBUs could work on a purely voluntary basis, and as mentioned, it is fundamentally different from pollution emissions because while $\mathrm{SO}_{2}$ emissions can only be "bad," the levels of animal well-being produced on a farm can be "good" or "bad." Perhaps a better parallel to the AWBU market are the existing voluntary (at least at the time of this writing) markets for $\mathrm{CO}_{2}$ emissions. To date there are no federal regulations forcing firms to limit $\mathrm{CO}_{2}$ emissions or for consumers to buy offsets, and yet there are several wellfunctioning markets. Two prominent examples are the Chicago Climate Exchange and the European Climate Exchange, in which companies and municipalities which emit Carbon can "offset" their emissions by buying credits produced by farmers and forest owners willing to make changes to store carbon. The markets also operate by emitters making a voluntary but legally binding commitment to an annual emission reduction target. Emitters who reduce below the targets have surplus allowances to sell or bank; those who emit above the targets comply by purchasing offsets.

Why would companies or municipalities participate in such a voluntary exchange? Some local municipalities (such as the city of Tulsa, Oklahoma) have responded to voter pressure to reduce emissions, and participating in the climate exchange is one way to fulfill those obligations. Moreover, it is good public relations for many companies to "go green" and reduce emissions to satisfy their customers. And there are those who, to satisfy their own conscience, purchase off sets (e.g., Al Gore). On the other side of the market are farmers and forest owners who see a profit opportunity available to store carbon. Despite the fact that these exchanges are voluntary, the world market for carbon trading is huge and involved more than $\$ 60$ billion in trades in 2006 (World Bank 2007). In much the same way as would happen were AWBUs traded, people willing to store carbon and sell offsets in the Chicago Climate Exchange make a legally-binding commitment which is verified or audited by an independent, third party organization.

Consider a final analogy. Just as many people care about the well-being of animals, many people care about the 
preservation of environmentally-sensitive or especially beautiful land. There are countless examples of people "putting their money where their mouth is" by forming land trusts to buy land and prevent development. Such conservation trusts use donations from interested parties to negotiate with land owners to acquire property. One of the biggest conservation trusts is the Nature Conservancy, which acquired and protected more than 15 million acres $\left(60,700 \mathrm{~km}^{2}\right)$ in the $\mathrm{US}^{10}$ Another example is the World Land Trust, established in 1989 in the UK, which claims to have purchased over 375,000 acres $\left(1,500 \mathrm{~km}^{2}\right)$ of land in Asia, Central and South America and the U.K. Interested parties can visit the World Land Trust's web site and donate $£ 25$, which purportedly will be used to acquire and preserve about 0.5 acres $\left(2,000 \mathrm{~m}^{2}\right)$ of rainforest. People making such a donation also receive a personalized certificate, a newsletter, and "the satisfaction of knowing that you have helped save threatened wildlife habitat forever."11

Returning to the issue of animal welfare, one might legitimately ask whether some people would really be willing to pay for AWBUs. As the case of land trusts suggests, the answer might be 'yes.' People donate billions of dollars each year to charities, and it seems logical to suggest that people might direct some of this money, either individually, or via the charities to which they donate, to purchasing AWBUs. Take, for example, the HSUS. The HSUS claims to have over 10 million members and constituents, and claimed revenues in excess of $\$ 120$ million in 2007. ${ }^{12}$ The HSUS claims to have spent over $\$ 112$ million in 2007 fighting on behalf of animals. Some of this money was spent in legislative battles and in other public relations campaigns that, at best, have an uncertain and indirect effect on animal well-being. Some of this $\$ 120$ million could have been spent on AWBUs which have a certain and direct effect on animal well-being. Of course HSUS is only one of numerous organizations interested in improving the well-being of farm animals.

Despite these arguments, the reality of the situation may be that such organizations would not want to participate in a market for AWBUs because they may feel that they can achieve the same outcomes through legislative and legal means without having to pay the costs. However, fighting legislative and court battles are costly, too. It was reported, for example, that supporters of Proposition 2 in California spent \$5.2 million in publicity campaigns (Sacramento Bee 2008). Such organizations are also likely to argue that they

\footnotetext{
$\overline{10} \mathrm{http} / / / \mathrm{www}$.nature.org/aboutus/howwework/conservationmethods/ privatelands/.

$11 \mathrm{http} / / / \mathrm{www}$. worldlandtrust.org/supporting/buyanacre.htm.

12 http://www.hsus.org/web-files/PDF/annual_report_2007_p1.pdf.
}

should not be the ones to bear the cost of the suffering imposed on animals. Nevertheless, a market for AWBUs provides a clear means to provide what the organization wants, and like all consumers, they should be willing to pay for what they want. Of course, organizations like HSUS or Farm Sanctuary are not the only potential demanders of AWBUs. Just as is the case for carbon offsets, it is possible that companies like McDonalds and Burger King might want to make public statements about their commitments to animal well-being by buying AWBUs at a volume proportionate to their use of animals. And, of course, any person, as an individual, might become a buyer of AWBUs if they were so inclined.

Finally, there is little reason for farm organizations to fight the creation of a voluntary market for AWBUs. And, indeed, many producers would likely participate given the opportunity to profit. If recent history has revealed anything, it is that farmers are willing to change production practices to supply what consumers want. Many farmers have completed processes to qualify for certification programs, adopted organic practices, or have stopped using growth promoters in animal production for no other reason than that there are some consumers who want such products and are willing to pay to have them. Organizations such as the American Farm Bureau or the National Pork Board would probably be somewhat relieved to avoid the costly (and likely unfruitful) state-by-state fights over ballot initiatives, and would welcome a system that allowed producers flexibility and freedom in choosing the levels of animal care that society demands.

\section{Summary}

Animal rights activists often decry the evils of the capitalist, market-based economy. Greedy corporate farms and agribusinesses have enslaved and mistreated billions of animals just to earn a few more dollars - or so the story goes. Market forces are powerful and no doubt the economic incentives that farmers have faced in the last 50 years have contributed to a reduction in animal wellbeing. But markets are only a means, not an end. Rather than demonizing the market, animal advocates could harness its power to achieve a worthwhile end. Although the idea of trading units of animal well being at first seems strange, as an economic concept it differs little from the standard economic approach that has been successfully used to mitigate environmental pollution. The animal units trading approach has several advantages over other policy proposals such as bans on certain production practices or meat taxes. One day, farmers and animal welfare advocates may leave the ballot boxes and courtrooms aside and hash out their differences in newly designed markets. 
Acknowledgments I would like to thank Damian Adams, Bailey Norwood, Glynn Tonsor, and Clem Ward for sharing their comments and suggestions on this topic. I also appreciated the helpful comments of the editor and three anonymous reviewers.

Open Access This article is distributed under the terms of the Creative Commons Attribution Noncommercial License which permits any noncommercial use, distribution, and reproduction in any medium, provided the original author(s) and source are credited.

\section{References}

Abrams, K.M., C.A. Meyers, and T.A. Irani. 2010. Naturally confused: Consumers' perceptions of all-natural and organic pork products. Agriculture and Human Values 27: 365-374.

Arrow, K.J., and G. Debreu. 1954. Existence of a competitive equilibrium for a competitive economy. Econometrica 22: 265-290.

Baumol, W.J. 1972. On taxation and the control of externalities. American Economic Review 62: 307-322.

Botreau, R., M. Bonde, A. Butterworth, P. Perny, M.B.M. Bracke, J. Capdeville, and I. Veisser. 2007a. Aggregation of measures to produce an overall assessment of animal welfare. Part 1: A review of existing methods. Animal 1: 1179-1187.

Botreau, R., M.B.M. Bracke, P. Perny, A. Butterworth, J. Capdeville, C.G. Van Reenen, and I. Veisser. 2007b. Aggregation of measures to produce an overall assessment of animal welfare. Part 2: Analysis of constraints. Animal 1: 1188-1197.

Bracke, M.B.M., B.M. Spruijt, J.H.M. Metz, and W.G.P. Schouten. 2002a. Decision support system for overall welfare assessment in pregnant wows A: Model structure and weighting procedure. Journal of Animal Science 80: 1819-1834.

Bracke, M.B.M., J.H.M. Metz, B.M. Spruijt, and W.G.P. Schouten. 2002b. Decision support system for overall welfare assessment in pregnant sows B: Validation by expert opinion. Journal of Animal Science 80: 1835-1845.

Carlsson, F., P. Frykblom, and C.J. Lagerkvist. 2007. Consumer willingness-to-pay for farm animal welfare: Mobile abattoirs versus transportation to slaughter. European Review of Agricultural Economics 34: 321-344.

Chang, J. B., J. L. Lusk, and F. B. Norwood. 2010. The price of happy hens: A hedonic analysis of retail egg prices. Journal of Agricultural and Resource Economics 35: 406-423.

Chilton, S.M., D. Burgess, and W.G. Hutchinson. 2006. The relative value of farm animal welfare. Ecological Economics 59: 353-363.

Conner, D.S. 2004. Expressing values in agricultural markets: An economic policy perspective. Agriculture and Human Values 21: $27-35$.

Cowen, T. 2006. Market failure for the treatment of animals. Society 43: $39-44$

De Mol, R.M., W.G.P. Schouten, E. Evers, H. Drost, H.W.J. Houwers, and A.C. Smits. 2006. A computer model for welfare assessment of poultry production systems for laying hens. Netherlands Journal of Agricultural Science 54: 157-168.

Hayek, F.A. 1945. The use of knowledge in society. American Economic Review 35: 519-530.

Fama, E.F. 1970. Efficient capital markets: A review of theory and empirical work. Journal of Finance 25: 383-417.

Francione, G.L. 2004. Animals-property or persons? In Animal rights: Current debates, new directions, ed. R. Sunstein, and M.C. Nussbaum. New York: Oxford University Press.
Francione, G. L. 2008. A losing proposition. About.com. August 26, 2008. http://animalrights.about.com/od/proposition2ca2008/a/ FrancioneProp2.htm. Accessed 5 October 2010.

Gallet, C.A. 2010. Meat meets meta: A quantitative review of the price elasticity of meat. American Journal of Agricultural Economics 92: 258-272.

Lusk, J.L., T. Nilsson, and K. Foster. 2007. Public preferences and private choices: Effect of altruism and free riding on demand for certified meat. Environmental \& Resource Economics 36: 499-521.

Lusk, J.L., and F.B. Norwood. 2011. Speciesism, altruism, and the economics of farm animal welfare. European Review of Agricultural Economics. Forthcoming.

Norwood, F.B., J.L. Lusk, and R. Pricket. 2007. Consumers share views on farm animal welfare. Feedstuffs 79(42): 14-16.

Norwood, F.B., and J.L. Lusk. 2011. Compassion by the pound: The economics of farm animal welfare. Oxford, UK: Oxford University Press.

Pigou, A.C. 1920. The economics of welfare. London: Macmillan and Co.

Regan, T. 2004. The case for animal rights. Berkeley: University of California Press.

Rollin, B.E. 2004. Animal agriculture and emerging social ethics for animals. Journal of Animal Science 82: 955-964.

Sacramento Bee. 2008. "Ballot watch: Proposition 2: Standards for confining farm animals." September 27, 2008.

Schmalensee, R., P.L. Joskow, A.D. Ellerman, J.P. Montero, and E.M. Bailey. 1998. An interim evaluation of sulfur dioxide emissions trading. Journal of Economic Perspectives 12: 53-68.

Stavins, R.N. 1998. What can we learn from the grand policy experiment? Lessons from $\mathrm{SO}_{2}$ allowance trading. Journal of Economic Perspectives 12: 69-88.

Singer, P. 2002. Animal liberation. New York: Harper Collins.

Sumner, D. A., J. T. Rosen-Molina, W. A. Matthews, J. A. Mench, and K. R. Richter. 2008. Economic effects of proposed restrictions on egg-laying hen housing in California. University of California-Davis Agricultural Issues Center Report, July 2008.

Sunstein, C.R., and M.C. Nussbaum. 2004. Animal rights: Current debates and new directions. New York: Oxford University Press.

Tonsor, G.T., N. Olynk, and C. Wolf. 2009. Consumer preferences for animal welfare attributes: The case of gestation crates. Journal of Agricultural and Applied Economics 41: 713-730.

Tweeten, L. 2010. Is there a high cost of 'cheap food' policies? Working Paper, Department of Agricultural, Environmental, and Development Economics, The Ohio State University.

Wise, S.M. 2004. Animal rights, one step at a time. In Animal rights: Current debates, new directions, ed. R. Sunstein, and M.C. Nussbaum. New York: Oxford University Press.

World Bank. (2007). State of the carbon market 2007. http://web. worldbank.org/WBSITE/EXTERNAL/NEWS/0,contentMDK:21 319772 menuPK:34463 pagePK:34370 piPK:34424 the SitePK:4607,00.html. Accessed 27 January 2011.

\section{Author Biography}

Jayson L. Lusk, PhD is Professor and Willard Sparks Endowed Chair in the Department of Agricultural Economics at Oklahoma State University. He has previously served on faculty at Purdue University and Mississippi State University. Dr. Lusk earned a PhD in Agricultural Economics from Kansas State University in 2000 and a BS in Food Technology from Texas Tech University in 1997. Lusk conducts research related to consumer behavior and decision making, food and livestock marketing and policy, and non-market valuation. 
Since 2001, Lusk has published over 100 articles in peer reviewed journals, has won several published research awards, and has been invited to present his research at over 20 Universities in the US and abroad. Lusk has served as associate editor for six academic journals including the American Journal of Agricultural Economics and the Journal of Environmental Economics and Management. Lusk recently co-authored a book on experimental auctions published by Cambridge
University Press and is also a co-author of an undergraduate textbook on agricultural marketing and price analysis published by PrenticeHall. He has a forthcoming book on the topic of animal welfare with Oxford University Press and he is currently co-editing the Oxford Handbook on the Economics of Food Consumption and Policy. 